\title{
EDITORIAL
}

\section{COVID-19, a Disease of Enigma: Why Pregnant Women are Less Vulnerable?}

\author{
Yifru Berhan, MD, Professor of Obstetrics and Gynecology \\ St Paul's Hospital Millennium Medical College, Ethiopia, Addis Ababa. \\ Email: yifruberhanm@gmail.com
}

Until proved otherwise, Covid-19 or SARS CoV2 infection is a disease of the century that turns the world upside down and inside out at multidimensional aspects of human life. Since its emergence, it has created a lot of confusion and uncertainty on its ultrafast speed of spread in the temperate climate zone and the bizarre course of the disease state. The so far relatively spared tropical countries may be explained by the humid and hot weather as it was the case for the majority of influenza and other human coronaviruses pandemics; for which, the less conduciveness of the weather for the survival of the SARS CoV-2 outside the human body may be attributed to.

In the interest of this editorial, the less morbid and less fatal nature of the Covid-19 to pregnant women has also opened a lot of discussions and countless speculations. This is because; while their immunity is weaker than nonpregnant women, the high resistance of pregnant women to Covid-19 is a paradox for many investigators.

What is known for bacterial and other viruses is that pregnant women are highly vulnerable to respiratory tract infections, partly because of the anatomic and physiologic changes, and partly because of the maternal immune modulation/suppression effect of pregnancy to tolerate an allograft fetus $(1,2)$. The T-helper 2 anti-inflammatory system dominance (elevation of IL-4, IL-10, IL-13 and TGF-beta) is a known physiologic adaptation to protect the fetus, but makes the mother and the fetus at higher risk for viral infection and serious complications (3). Interestingly, this is not conspicuously observed in the case SARS CoV-2 infection.

Even among coronaviruses, SARS $\mathrm{CoV}$ and MERS $\mathrm{CoV}$ have caused relatively higher maternal morbidity and mortality since they were recognized as human pathogen in 2002 and 2012, respectively. As small-scale studies showed, among five SARS CoV infected pregnant women, two required mechanical ventilator, one required dialysis and one developed convulsion, but all recovered from their illness. Another study showed that the case fatality rate of SARS CoV was $25 \%$ and obstetric complications were significant (4). Almost comparably, five of 13 MERS CoV infected pregnant women required mechanical ventilator and 3 died (5).

Unlike SARS CoV and MERS CoV, none of 38 pregnant women with Covid-19 infection developed severe pneumonia or died of other complications, even those with underlying morbidity (hypertensive disease in pregnancy, gestational diabetes, influenza, hypothyroidism) (6). In this study, reported perinatal complications were not related to Covid-19. An investigation of 147 pregnant women (64 confirmed, 82 suspected and 1 asymptomatic with COVID-19) by the World Health Organization delegates also concluded that pregnant women were not at higher risk for developing severe disease due to SARS CoV-2 infection (7). A recent systematic review of 108 pregnant women reported that 3 required intensive care unit admissions, but there was no maternal death (8)

Further, unlike many viral infections (including Zika virus, Ebola virus, Marburg virus, Rubella and Cytomegaloviruses), vertical transmission was not previously reported from SARS CoV, MERS $\mathrm{CoV}$ and SARS CoV-2 infections, even in the presence of obstetric risk factors (premature rupture of fetal membranes, preeclampsia and vaginal operative deliveries) (6, $8,9)$. Many authors are not yet convinced with the recently reported neonates as SARS-CoV-2 positive following delivery in the range of some minutes to 30 hours, to consider them as cases of vertical transmission. Similarly, some authors 
have associated miscarriage, fetal growth restriction and preterm delivery with Covid-19 $(10,11)$; however, other authors have attributed these complications to the underlying obstetric disorder $(2,4,6)$ or stated it as warranting further investigation (8).

Although what protects pregnant women from developing severe Covid-19 remains being enigmatic, the difference in immunologic response may partly explain for the difference in the severity of maternal illnesses. Patients who developed SARS CoV characteristically and preferentially showed activation of Th1 immunity, thereby resulting in a significant elevation of proinflammatory cytokines (IFN $\gamma$, IL-1 $\beta$, IL-6 and IL-12) that leads to extensive lungs damage (12). That is; the unilateral activation of the Th1 immunity may give chance for the proinflammatory cytokines dominance over the anti-inflammatory cytokines and cells, leading to what is called "cytokine storm".

The immunologic response to women with Covid-19, however, is activation of both Th1 and Th2 immunity (13), which is probably an advantage to balance the pro- and antiinflammatory mediators. Therefore, the author's assumption for the less vulnerability of pregnant women to Covid-19 is the counter effect of the already matured and further accentuated Th2 immunity. The Th2 response is further enhanced by the markedly elevated anti-inflammatory and immune modulating hormones (like adiponectin, prostaglandins, estrogen, progesterone, corticosteroid) and other proteins like leukemic inhibitory factor, which all are favoring Th2 immunity activation and Th1 inhibition (14-16).

As a result, the TH2 response may remain dominant even after developing Covid-19, thereby reducing the risk of inflammatory reaction, which is responsible for severe pneumonia/ARDS and systemic damage (17). Advancing pregnancy is also characterized by a shift from inflammatory macrophages (M1) and natural killer cells (in early stage of pregnancy) to anti-inflammatory macrophages (M2), which secretes IL-10 and TGF-beta, and promotes the $\mathrm{TH} 2$ response and damaged tissue healing $(16,18)$. Further, what makes pregnancy special is the high level of IL-10 from multiple pregnancy related (placenta and decidua) additional cellular sources (trophoblasts, uterine natural killer cells, monocytes, and $\mathrm{T}$ regulatory cells). As a result, it is noted that IL-10 levels increase markedly starting from the first trimester and remain elevated till the end of the third trimester (19), which is probably the major determinant factor for the less aggressive nature of Covid-19 in pregnancy.

The weak inflammatory response during pregnancy (as a result of Th1 suppression) is known to worsen influenza, malaria and SLE (Th2-type autoimmune disease). To the contrary, many of the Th1 and Th17-type autoimmune diseases (including multiple sclerosis, rheumatoid arthritis, Graves' disease, the myasthenia gravis) undergo a remarkable remission during pregnancy and flare up in the postpartum period (14). Such phenomena seem as well replicable to Covid-19. There is large body of data, which described the damage due to Covid-19 is not due to direct effect of the virus to the cells; rather, due to the immunopathogenic effect of the virus, mimicking autoimmune diseases, and usually occurring after the second week of infection or after the virus shedding is minimal (20). This is despite the fact that females are at higher risk of autoimmune disease, for which the extra X-chromosome is implicated (21). The implication is that pregnant women have a cumulative advantage for not to have a worsening illness of the Covid-19, like the Th1 and Th17-types of autoimmune diseases.

One may also argue that age is a factor for the less morbid and less fatal nature of the Covid19 in pregnant women (who usually conceive in $<40$ years of age) as the severity of this virus and its cousins (SARS $\mathrm{CoV}$ and MERS $\mathrm{CoV}$ ) were associated with increased age (22). No person died under the age of 24 years during the 2002-2003 SARS CoV pandemic. In the general population, it is well noted that the severity of the Covid-19 illness and mortality are positively correlated with age. Unlike influenza virus, children and young persons are less vulnerable $(<1 \%)$ to all types of the fatal human coronaviruses (OC43, SARS CoV, MERS CoV and SARS CoV-2) complicating with severe pneumonia and $\operatorname{ARDS}(23,24)$. Inoculation of SARS CoV and SARS CoV-2 to experimental animals has also shown early detection of the virus in the nasal swab in the young and increased lungs lesion and prolonged viral shedding in the aged animals (22).

In general, there is a large body of observational data that has shown the non-life- 
threatening effect of Covid-19 to pregnant women, for which the immune-hormonal physiologic changes seem exceptionally protective from the SARS CoV-2 fatal injury to the respiratory and other organ-systems. Studying in depth the hormonal and immunological responses of pregnant women to SARS CoV-2 is probably one step forward to identify the key factors that switch off the disease progress at certain point. In particular, the therapeutic or prophylactic role of IL-10, which has both anti-inflammatory and antifibrotic action in resident lung cells and others (25), is an area of interest for research to explore its action on SARS CoV-2.

The current issue of the journal, the third regular issue for the year 2020, contains twelve original articles, three reviews and a correspondence focusing on various topics. The correspondence written by one of the eminent researchers and clinician details on the effect of the current pandemic-COVID-19 on Africa and the tropics. We recommend everyone to read it and forward comment if any.

\section{REFERENCES}

1. Lam CM, Wong SF, Leung TN, Chow KM, $\mathrm{Yu}$ WC, Wong TY, et al. A case-controlled study comparing clinical course and outcomes of pregnant and non-pregnant women with severe acute respiratory syndrome. BJOG, 2004;111(8):771-774.

2. Wong SF, Chow KM, Leung TN, Ng WF, Ng TK, Shek CC, et al. Pregnancy and perinatal outcomes of women with severe acute respiratory syndrome. Am J Obstet Gynecol, 2004;191(1):292-297.

3. Berger A. Th1 and Th2 responses: what are they? BMJ, 2000:321;424.

4. Schwartz DA. COVID-19, SARS-CoV-2 and pregnancy: Does the past predict the present? Accessed April 24, 2020 from: https://www.contagionlive.com/news/covid1 9-sarscov2-and-pregnancy-does-the-pastpredict-the-present.

5. Rasmussen SA, Smulian JC, Lednicky JA, Wen TS, Jamieson DJ. Coronavirus Disease 2019 (COVID-19) and pregnancy: what obstetricians need to know. Am J Obstet
Gynecol, 2020; S0002-9378(20)30197-6. https://doi.org/10.1016/j.ajog.2020.02.017.

6. Schwartz DA. An Analysis of 38 Pregnant Women with 2 COVID-19, Their Newborn Infants, and Maternal-Fetal Transmission of SARS-CoV-2: Maternal Coronavirus Infections and Pregnancy Outcomes. Arch Pathol Lab Med, 2020. doi: 10.5858/arpa.2020-0901-SA.

7. World Health Organization. Report of the WHO-China Joint Mission on Coronavirus Disease 2019 (Covid-19). Accessed April 24, 2020 from: https://www.who.int/docs/defaultsource/coronaviruse/who-china-joint missionon-covid-19-final-report.pdf

8. Zaigham M, Andersson O. Maternal and perinatal outcomes with COVID-19: A systematic review of 108 pregnancies. Acta Obstet Gynecol Scand. 2020; 00:1-7. DOI: 10.1111/aogs.13867. Accessed April 24, 2020 from:

https://obgyn.onlinelibrary.wiley.com/doi/pdf /10.1111/aogs.13867.

9. Alserehi H, Wali G, Alshukairi A, Alraddadi B. Impact of Middle East Respiratory Syndrome coronavirus (MERS-CoV) on pregnancy and perinatal outcome. BMC Infect Dis, 2016;16:105.

10. Dashraath P, Jing Lin Jeslyn W, Mei Xian Karen L, Li Min L, Sarah L, Biswas A, et al. Coronavirus Disease 2019 (COVID-19) Pandemic and Pregnancy. Am J Obstet Gynecol, 2020. doi: https://doi.org/10.1016/j.ajog.2020.03.021.

11. Di Mascio D, Khalil A, Saccone G, Rizzo G, Buca D, Liberati $M$, et al. Outcome of Coronavirus spectrum infections (SARS, MERS, COVID 1 -19) during pregnancy: a systematic review and meta-analysis. Am J Obstet Gynecol MFM, 2020; doi: https://doi.org/10.1016/j.ajogmf.2020.100107

12. Wong CK, Lam CWK, Wu AKL, Ip WK, Lee $\mathrm{NL}$, Chan IH, et al. Plasma inflammatory cytokines and chemokines in severe acute respiratory syndrome (SARS). Clin Exp Immunol, 2004; 136 (1):95-103.

13. Huang C, Wang Y, Li X, Ren L, Zhao J, Hu Y, Zhang L, et al. Clinical features of patients

DOI: http://dx.doi.org/10.4314/ejhs.v29i5.1 
infected with 2019 novel coronavirus in Wuhan, China. Lancet, 2020;395:497-506.

14. Shah NM, Lai PF, Imami N, Johnson MR. Progesterone-Related Immune Modulation of Pregnancy and Labor. Front. Endocrinol, 2019.10:198. doi: 10.3389/fendo.2019.00198.

15. Bränn E, Edvinsson Å, Rostedt Punga A, Sundström-Poromaa I, Skalkidou A.

Inflammatory and anti-inflammatory markers in plasma: from late pregnancy to early postpartum. Sci Rep, 2019; 9(1), 1863. https://doi.org/10.1038.

16. Robinson DP, Klein SL. Pregnancy and pregnancy-associated hormones alter immune responses and disease pathogenesis. Horm Behav, 2012; 62(3): 263-271.

17. Gibson PG, Qin L, Puah S. COVID-19 ARDS: clinical features and differences to "usual" pre-COVID ARDS. Med J Aust, 2020; https://www.mja.com.au/journal/2020/ covid-19-ards-clinical-features-anddifferences-usual-pre-covid-ards [Preprint, 24 April 2020].

18. Mantovani A, Biswas SK, Galdiero MR, Sica A, Locati M. Macrophage plasticity and polarization in tissue repair and remodeling. The Journal of pathology, 2013; 229, 176185.

19. Abdulamir AS, Hafidh RR. The Possible Immunological Pathways for the Variable Immunopathogenesis of COVID-19 Infections among Healthy Adults, Elderly and Children. Electron J Gen Med. 2020;17(4): em202. https://doi.org/10.29333/ejgm/7850

20. Itoh Y, Golden LC, Itoh N, Matsukawa MA, Ren E, Tse V, et al. The X-linked histone demethylase $k d m 6 a$ in CD4+T lymphocytes modulates autoimmunity. JCI, 2019; Accessed on April 24, 2020 from: jci.org/articles/view/126250.

21. Rockx B, Kuiken T, Herfst S, Bestebroer T, Lamers MM, de Meulder $M$ et al. Comparative pathogenesis of Covid-19, MERS and SARS in a non-human primate model. https://doi.org/10.1101/2020.03.17.995639.

22. Guan W, Ni Z, Hu Y, Liang W, Ou C, He J et al. Clinical characteristics of coronavirus disease 2019 in China. N Engl J Med. DOI: 10.1056/NEJMoa2002032. Accessed on April 242020 from:
https://www.nejm.org/doi/full/10.1056/NEJ Moa2002032.

23. Zhou P, Fan H, Lan T, Yang X-L, Shi W-F, Zhang W, et al. Fatal swine acute diarrhoea syndrome caused by an HKU2-related coronavirus of bat origin. Nature, 2018, 556(7700): 255

24. Steen EH, Wang X, Balaji S, Butte MJ, Bollyky PL, Keswani SG. The Role of the Anti-Inflammatory Cytokine Interleukin-10 in Tissue Fibrosis. Advances in Wound Care, 2020; 9(4):184-198 http://doi.org/10.1089/wound.2019.1032

25. Thaxton JE, Sharma S. Interleukin-10: A Multi-Faceted Agent of Pregnancy. Am J Reprod Immunol, 2010; 63(6): 482-491. 